\title{
A comunicação entre crianças, pais e treinadores* na escolinha esportiva de basquetebol em aulas e eventos esportivos - a perspectiva a partir dos sujeitos
}

\section{Resumo}

Este estudo foi realizado com crianças, pais e treinadores de uma escolinha esportiva de Basquetebol, em aulas e eventos esportivos. A referida escolinha faz parte de um programa de iniciação esportivada Secretaria Municipalde esportes, recreação elazer de PortoAlegre (SME). Éde corte qualitativo, descritivo, um estudo do tipo etnográfico. Oproblemado estudofoi: Comoocorre a comunicação entre crianças, pais e treinadoresnaescolinha esportivade Basquetebol, emaulase eventos esportivos?

O estudoficou organizado em referencial teórico, decisõesmetodológicas, análise e interpretação das informações que foramobtidas através das observações, entrevistas semi-estruturadas, diário de campo e análise de documentos.

A partir das informações surgiram 265 unidades de significado que aproximadas portemáticas foramobtidas três categorias de análise.

Palavras-chave: comunicação, crianças, pais, treinadores, escolinha esportiva.

\section{Abstract}

This study had as its main purpose the analysis and interpretation of the means by which communication between children, parents and trainers occursinclasses and sporting events of the basketball school of the PortoAlegre County Secretariat ofSports, Recreation and Leisure. For the development of the research themethodological principles that guide a
MarisaMendesGö̈tze**

BennoBeckerJr***k

qualitative researchwere used, being a study of the ethnographic type. As an instrument to collect information, visual observation, semi-structuralized interviews, field journals and document analysis were used. The analysis and interpretation of the information was carried through the following categories of analysis: communication between children and parents about the reasons that lead the child to adhere to basketball sporting school; communication between parents and trainers about the purpose of the school; and communication between the children, parents and trainer in classes and sporting events.

Keywords: communication, children, parents and trainers and basketball school.

\section{Resumen}

Este estudio fue realizado con niños, padres y entrenadores de una escuela ("escolinha") de Básquetbol, enaulasyeventosdeportivos. Dichaescuela participade un programade iniciación deportivade la "SecretariaMunicipaldeEsportes, Recreaçãoe Lazer de PortoAlegre" (SME). Es de corte cualitativo, descriptivo, unestudio de tipoetnográfico. Elproblemadel estudiofue: ¿Cómoocurrelacomunicación entre niños, padres y entrenadores en la escuela deportivade Básquetbol, enaulasyeventos deportivos? El estudio fue organizado en referencial teórico, decisionesmetodológicas, análisis einterpretaión de las informaciones quefueron obtenidas a través de lasobservaciones, encuestassemiestructuradas, diario decampoyanálisis de documentos. 
A partir de las informaciones surgieron 265 unidadesdesignificado que aproximadasportemáticas fueronobtenidas tres categoríade análisis.

Palabras-clave: comunicación, niños, padres, entrenadores, escueladeportiva("escolinha").

\section{Introdução}

Opresenteestudotevecomofinalidade verificaracomunicaçãoentre crianças, paise treinadores*deuma escolinhaesportivade Basquetebol, duranteas aulase oseventosesportivosnaperspectivadesses sujeitos.

Atravésdaanáliseeinterpretaçãodasinformações, sem apretensãode fazergeneralizações, serão colocadas algumasinterpretações queforamsignificativas arespeitode comoocorreu acomunicaçãoentre as crianças, paise treinadoresnessecontextoquefazpartede um programadeiniciaçãoesportivadestinado acomunidadedePortoAlegre.

Égrandeonúmerode criançasque iniciamtodos os diasalgumaatividadeesportiva. Essainiciaçãoocorre muitas vezesnaescolaesecomplementaemescolinhas esportivas,nogerallocalizadaemumclubeesportivo, escolaparticular ou centrocomunitário.

Asescolinhasestão distribuídas por vários pontos da cidade, cadaumacomsuaespecificidade. Sãocoordenadasoudirigidas porprofessores deEducaçãoFísica, acadêmicosdeEducaçãoFísicaouex-atletas(BECKER JR.2000a).Entre os objetivosquedesejamalcançar, estão,ensinarumamodalidade esportiva ouaperfeiçoá-la,comporumaequipeparaparticipardecampeonatosouaindaoportunizaraumacomunidadeque nãotenhacomopagarumclubeesportivoodireitode praticarumesporte. Asescolinhasesportivas sãouma maneiradeocuparotempolivre das crianças que ficamdentrodecasasempoder brincarnarua. Como aumentodesenfreadodascidades,pincipalmentenum grandecentro, acabaram-seas brincadeiras derua, os "campinhos" que havianas cidades antigamente; $\mathrm{e}$ ascriançasforamficandocadavezmaisdentrodecasa.
Dessemodo, asescolinhas esportivas passaramaser alternativas paraesses pais deixarem seus filhosocuparemashoras livres, aprendendoalgumamodalidade esportiva ou até mesmo servindo de lugar para deixá-lasquandoelestêmalgum compromissosocial ouprofissional(BECKERJR.,2000a).

As análiseseinterpretações dasfalas dos sujeitosenvolvidos naquele contextojuntamente com anossa subjetividadenosfazempensarqueesseestudopoderiacontribuirparaque novas investigações possam surgirnaintençãode aprofundaroreferidotemaque foi a comunicaçãoentre crianças, paise treinadores.

\section{A comunicação}

A linguageméoque diferenciaohomemdos outros animaise semalinguagem seriaparaeleimpossível demonstrar sua cultura, sua história ou sero que ele é.Atravésdacomunicaçãosãocompartilhadosmodos devida, pensamentos, atitudesecomportamentosque podemserfeitospormeiode umalinguagemnaformaverbaldeacordocomcadapessoa, culturaeclasse social(DELPRETTE, 1999). Aosereferiràcomunicaçãona sociedade essamesmaautoradizqueelaéresponsável pelaformação de extensas redes de trocas sociais que são capazes de dar continuação a uma culturaou modificararealidade social. A maioriadas pessoasocupaseutempocominteraçõessociaisemesmoaquelas que vivemmais sozinhassentemnecessidadedeteressescontatoscomcolegas oupessoas amigas. Para que essas interações ocorram de maneira efetivadependem dacomunicaçãoentreessas pessoas.(DELPRETTE, 1999).

Acomunicaçãoverbal, utilizada nocotidianooufora delepossui signosqueregulamointercâmbioverbale possibilitamacompreensãodoqueéfalado.(DAVIS, 1979.Elas sãoapenasoinícioe, segundoacitadaautora, existeumsolofirme alémdaspalavrasemquese constroemasrelaçõeshumanasqueéacomunicação não-verbal. 
ParaDelPrette, 1999, acomunicaçãoverbal podeestar presente ou não quando nos comunicamos, enquanto que a comunicação não-verbal estásempre presentee, segundoessaautora, sãoutilizados $65 \% \mathrm{de}$ componentesnão-verbais,e $35 \%$ de verbais, quando alguém secomunica.

Acriança, mesmoantesdefalar, utiliza-se deformas não-verbais de comunicação; antes de aprenderafalar a sua comunicação se faz por intermédio de seu corpo;noentanto,nomomentoquehámanifestações dafala,essasmensagenscorporaissãodeixadasdelado pelas pessoas que cercama criança, comose elasnão maisexistissem.

Conforme RectoreTrinta, (1993)ocomportamento daexpressãodoserhumanonão se limitaaos gestos, apostura ou movimentos que ocorpo ofereça. Ea interação social tem situações definidas por características culturais. Isto ocorre através das normas que regemocomportamentodeumasociedade.

Ocomportamentonão-verbal não apenasseajustaà expressãolingüística, comotambémrevelaaexpressão de intençõese o estado afetivo das pessoas. Ela incide sobre as relações interpessoais, regulandoa interaçãoe proporcionandoocontraste de atitudese personalidadesindividuais. Comomovimentodeseu corpo,ohomemexpressasuaemoçãodemaneiratão evidentequenãotemcomodisfarçá-los verbalmente. Confirmandoisto: "Ogestoé, portanto, uma ação corporal visivel pela qual um certo significadoé transmitido por meio de expressão voluntária" (RECTOReTRINTA1993.p23).

Todosesses gestostêmgrandeinfluêncianas pessoas queseenvolvemnocontextoesportivo.SegundoBecker Jr.(2000a),noesportehámuitasexpressõesfeitascom ocorpo como: aplaudir, elevaro polegar, apertar as mãos. Segundooautorotreinadorprecisaterboacomunicaçãocomseusatletas. Oconteúdoverbal de sua faladeveestardeacordocomasualinguagem corporal. Seissonãoocorrerécertoqueestaráacontecendo uma comunicação ambígua que irá prejudicar as interações entreotreinadore os atletas, poisessaserá logopercebida. A mensagemdaáreaverbal seráanuladapelanão verbal.

Concordando com o que disse o autor anterior, WeinbergeGould(2001)referiram-se dessaformaa comunicaçãonão-verbal.

"Mensagensnão-verbaissãomaisdificildeesconderecontrolarconscientemente do queasmensagensverbais; portanto, elasmuitasvezes são indicadoresprecisos de como umapessoasesente"(WEINBERGeGOLUD,2001.p231).

ParaWeinbergeGould(2001),provavelmenteoque ocomecomasmensagensnão-verbaisnãoestejam sob onossocontroleconsciente, revelandonossasatitudes esentimentos, porissosetoma difícilescondê-las.Dizemqueàmaneira comosefala, aqualidade da voz trai osnossos sentimentos, oestadodehumor, declarandoverdadeiramente oque estamos sentindoeque nãoqueremos, muitas vezes, declararverbalmente.

Paraoserhumanoaose comunicarcom seus semelhantes, eleutilizazonas decomunicaçãoquesãochamadas de proxêmica; sendoassim, eleaosecomunicar fica próximo ou distante de quem está falando. (BECKERJR,2000a).

Paraesteautor,nocontextoesportivo os treinadores muitas vezes gritam durante as competições eos treinamentos, atribuindoessas causasà distânciaemque seencontramdeseus atletas. Tivemosocasiãode verificar issoporparte deumfamiliar de um garotoque atuava naescolinha; a pessoa estava ao nossolado, assistindosimultaneamenteojogode basqueteboleo jogodefutsal.Nojogodefutsal, otécnicogritavacom as crianças, eo familiar, ao serperguntadocomopercebia da conduta daquele treinador, disse: "Técnico tem que gritar com os jogadores, porque todos os técnicos gritam" "Interpretamosaspalavrasdessapessoa como sendo atitudes que elas vêem através da mídia: de tanto serem repetidas, acabam porserem vistas comonormais, mesmoestandoerradas.

BeckerJr.(2002)confirmaisto, quandorelataque, mesmonosesportesqueotreinadorficapróximodeseusatletas, elescontinuamgritando.Talcondutalevaaumaperdadeenergiainútil,eacomunicaçãoficaprejudicada. 
"Ogritolevaoatletainconscientementeaprotegerse, contraindo a musculatura corporal comouma espécie de armadura e rejeitar oconteúdo que está embutidonessaexpressão emocional"'(BECKERJR., 2000ap. 92).Enosdizque conhecer a pára-linguagemecomousá-laéimportante paraqueotreinador nãoprejudique,comsuaconduta, acomunicaçãocom ogrupo.

Umacomponenteimportantenacomunicaçãoéaescuta ativa. Quando ouvimos alguém, utilizamos a nossacomunicaçãonão-verbal queéocontatoocular diretoeformasdeacenarparademonstrarqueestamos interessados no assunto que estamos escutando (WEINBERGeGOULD,2001).

Muitas vezesa comunicaçãoineficazpode sercausadapormensagensambíguasquesãodadas através da falaverbal,masquenãocondizcomanossamensagemcorporal.Quandonoscomunicamoscomoutras pessoaséimportanteenviarmosmensagensefetivas ${ }^{2}$, tanto verbaiscomonãoverbais, poisatravésdacomunicação efetiva resultam em interações positivas. (WEINBERGeGOULD,2001).

Segundo Rectore Trinta(1993), quandonos referimosàcomunicaçãonão-verbal parecequeelaévista comoumcomplementodoprocessodecomunicação. Masoque ocorre, segundoestes autores, éque, quandonoscomunicamos, ouvimos anósmesmoscomo ouvimos os outros, mas nãonos vimos. E, segundo eles,essasduasformasdenoscomunicarmosnãoocorrem dissociadas uma daoutra, elasfazempartedalinguagem, a comunicação verbal pela lingüística ea comunicaçãonão-verbal pelos significadosdaexpressãocorporal daspessoas.

EstudosdeMehrabianapudBeckerJr.(2000a), ressaltam que as mensagens feitas através dafalatêmnos componentesverbais $7 \%$, altemâncias vocais $38 \%$ eexpressõesfaciais $55 \%$.Comopodemosobservar,amaioriadas mensagensétransmitidaatravés daáreanãoverbal.Existemoutrasformasdenoscomunicarmosque nãoapenasalinguagem verbal, comonos dizeste au- tor: "Alinguageméobviamenteessencial aos seres humanos, masnãonos contaa história todadacomunicaçãohumana"(MILLER, 1978,p.248).

\section{Reforços na comunicação}

Aspessoasnecessitamreceberfeedbackdesuasações, quandoestãorealizandoumaatividade.Levando-se paraa práticaesportiva, paraquesecrie umambiente que promovaoprazernocrescimento, domíniodas habilidadesecapacidades, os profissionais doesporte investememtécnicas demotivaçãoque sãobaseadas nos princípios doreforço.

ParaosPsicólogosdoEsporteexistemformaspositivase negativasde ensinar.Oreforçopositivoébaseadoem recompensarocomportamentoadequadodas pessoas, aumentandoa probabilidade de elas repetiremesses comportamentos. Aocontrário, aabordagemnegativa focaliza-seempunircomportamentosindesejáveis, oque provavelmentelevariaaumareduçãodessescomportamentos. Comoaabordagemnegativafocaliza-senos errosetentaeliminaressescomportamentosnegativos por meiode puniçãoe crítica, a motivação paraesse compatamentoéomedo(WEINBERGeGOULD,2001). Asrecompensasdevemsatisfazernecessidadesdaspessoasque as recebem. Porissoéimportanteque seconheçaogostodaquelescomquemsetrabalha, parase utilizar reforçosdeacordocomcadaum.

Algunsexemplosdereforçosefetivos segundoesses autores:

- Reforçadoressociais:elogios,sonisos,cumprimentos,publicidade.

- Reforçadoresmateriais: troféus,medalhas,faixas, camisetas.

- Reforçadoresdeatividade:jogarememvezdetreinar,jogarem posiçãodiferente, fazerumaviagem parajogarcomoutrotime, descansar.

- Saídasespeciais: iraumjogo profissional, planejarumafestadotime, assistiraumaapresentação deumatletaprofissional. 
Oselogiosverbaisenão-verbaissãomuitoimportante para otimizara comunicaçãoentre as pessoas. Oelogioverbalfavoreceofeedback positivoeajudaosatletas aprocuraremfazeromelhor.Umsimplescumprimentopelobom trabalhopodeseroreconhecimento deque elecontribui paraotimeouatépararealização deumobjetivopessoal.

Antes denos encaminharmos parao próximoitem onde trataremosdocontextoestudado, percebemos através das reflexões que realizamos comos vários autores anteriores, oquantoéimportante haveruma comunicaçãoefetiva entreas pessoas.

Para que sejaalcançadaessa otimizaçãona comunicaçãoénecessáriodesenvolvermosessas habilidades decomunicaçãofornecendo “feedback” positivos as pessoas com quem estamos nos comunicando. (WEINBERGEGOULD,2001).

\section{O contexto estudado: a escolinha esportiva de basquetebol da SME}

Quandooptamos porrealizaronossoestudoemum contextode escolinha esportiva comunitária, não sabíamosqueoesporteparaacomunidadejáacontecia hámuitotempoemPorto Alegre.

Voltandoumpoucoaumpassadorecente, paramelhornos situarmos nas práticas esportivas dirigidasà comunidade em Porto Alegre, encontramos sinais muitofortes de quearecreaçãopública existiadesde 1926. A iniciativa partiu de um professor chamado FredericoG.Gaelzerquetinhaapreocupaçãoemorientaraspessoas pararealizaratividadesesportivas para ocuparemseutempolivre. Esse trabalhoteve início emumadaspraçasquetinhaonomede "AltodaBronze",hojepraçaGeneral Osório(GAEL ZER, 1985).

Noanode 1955aSecretariaMunicipaldeEducaçãoe CulturaPopularesuperintendênciadeEnsinoMunicipal, originariamos Setores de Jardins de Recreação Públicacomsetoresesportivos:as praças.
SegundoRodrigues(2000), todososespaços públicos delazeresportivos até 1989estavamnazonacentral dacidadedePortoAlegreeeram 16 praças. Os professores deEducaçãoFísica trabalhavam comaprendizagemesportivas de diversas modalidades, sobaformadeescolinhas.

Através do orçamento participativo foi priorizadaa construçãodemódulosesportivosnazonadeperiferia dacidade, sendoassim descentralizadootrabalhode esportes nacidadeparaoutras zonas.

Em 1993,jáeram 32 praçase 90professoresqueatuavamnotrabalhodasupervisãodeEsportese RecreaçãoPúblicae tinhaum vínculocomaSecretariaMunicipal deEducação(SMED). Houvenecessidade de sercriada umaSecretariaque tratasse da Recreação, Esportee Lazer, sendoentão criada a atual SMEno anode 1994, queatualmentemantémumnúmerode 110 professores e 25 estagiários deEducaçãoFísica, responsáveis pelaexecuçãode todas as atividadesrelacionadascomesportes.

\section{Unidades recreativas}

UnidadesRecreativas significamos locaisem praças, ginásioeparques emqueaSMEadministra osespaçospúblicos, comoasescolinhasesportivas, grupos de convivência, festas comunitárias, atividades recreativas, promovendojogos, torneiose campeonatos nas praças(RODRIGUES,2000).

Ingresso das crianças às escolinhas esportivas

Durante operíodo de férias são realizadasinscrições dos alunos interessados em praticaralgumamodalidadeesportiva. Antes deiniciaroperíodo de aulasna escolinhaérealizadoum sorteio, aberto ao público, para determinar quemocuparáas vagas damodalidadequeescolheu. Tivemosaoportunidadedeacompanhar areferidaatividade. Cadamodalidaderealiza osorteioemum diadeterminado. 
Ostrabalhos relacionados comoesportenaPrefeitura dePortoAlegrefundamentam-seemDiretrizesPedagógicas articuladaseconstruídas porum trabalhoconjuntodos professoresque compõeaSME. Pudemos constatarisso através do documento aque tivemos acesso, oque balizaas açõese otrabalho daSME,na áreadolazeresportivo/recreativo; segundoessedocumento,équeasintervenções didáticaspedagógicasda SMEsãodefinidasdeacordocomascaracterísticasda própria clientelae, para o trabalho, éadotada uma referênciaque sãoasfaixas etárias.

Nocasodo Basquetebol para afaixa etária de deza dozeanos, aque nos propomosaestudar, osobjetivos estãoexplícitosnosplanosdeensinoquesãofeitospelos professoreseque seencontramjuntoàcoordenação pedagógicadasUnidadesRecreativas.

Oseventosesportivosparaestafaixaetániatêmoperfilde encontros, ondesãoconvidadostodososlocaisquepossuemescolinhasdebasqueteboldaSME, algunsclubesesportivos e escolas da cidade. Nesses encontros são vivenciadasasregrasdoMini-Basquetebol, todasascriançasarremessamumaveznofinal dos jogoseospais entramemquadraearemessamparaasequipesdeseus filhos, convertidosos pontosparaasequipesdascrianças. Duranteas aulas comafaixa etária(crianças), aintervençãodoprofessorémais marcante, caracterizandoa estururuadeaula.(DiretrizesPedagógicas2000). Quanto àfrequiência,sãoregistradas peloprofessordaescolinha todososdiasnaaula. Ascriançasnãopodemtermaisde trêsfaltas nomês, sobpenade perdera vaga, tendode inscrever-sedenovoeesperaroutrosorteio.Paraosalunosmenoresdecatorzeanos, as atividadessãogratuitas.

\section{Decisões metodológicas}

Nasúltimasdécadascomograndenúmerodecrianças aderindoàsatividadesesportivas,nocampodainvestigação,surgiuapreocupaçãoemrealizarumestudoque severifiqueapartirdaperspectivadessessujeitos, oque ocorrenessecontextodacriançanoesporte.
Assim, opresenteestudoverificouacomunicaçãoentre as crianças, pais e treinadores de uma escolinha esportiva de basquetebol, da SecretariaMunicipal de Esportes,RecreaçãoeLazerdePortoAlegre(SME),nas aulasenoseventosesportivos. Oproblemadainvestigação ficou definidodessaforma:

Considerandoaárea deinteressedoestudoeprincipalmente osobjetivosformulados, a trajetória metodológica aqui delineada, fundamenta-se no paradigma interpretativo-qualitativo, comespecialenfo-

Comoocorreacomunicação entre as crianças, os pais e os treinadores, em umaescolinhaesportivade basquetebol, nas aulase nos eventos esportivos da SecretariaMunicipaldeEsportes, Recreaçãoe Lazer, doMunicípiode PortoAlegre(SME)? que numestudodo tipoetnográfico.

Esse estudo caracterizou-se por serexploratório, em umprimeiromomento; nele pretendemosdescrevero fenômenoe as possíveis relações que se processaram nocontexto focalizado.Parafundamentá-lofomos buscar apoio em Triviños (1987. p.109), quando enfatiza "queosestudos exploratóriospermitemao investigador aumentar sua experiência em torno de um determinado problema".

Esseprocesso,nopresente estudo, ocorreuquandofizemos aproximaçõespreliminares, ou seja, após decidironderealizaríamosoestudo; fomos atéasUnidadesRecreativasondesedesenvolviamostrabalhoscom asescolinhasesportivas,paraconhecê-las.

A escolhadoparadigma qualitativo foi feita, pois se tratavadeum temacomplexoesubjetivoqueenvolvia ascrenças, os valorese as convicções dos sujeitosenvolvidos. Umestudoque segundonossaopiniãonecessitaria váriasidas aocampo, falarcom as pessoas envolvidas,participardaquelesmomentosemqueeles sãoatoresemumdeterminadocontexto.

ConformeafirmaNegrine(1999.p.61): 
"Mais recentemente a etnografia, comomodelo viável de investigação dentro de uma perspectiva de paradigma qualitativo, passa a ser utilizada no campo da educação, fundamentalmente em estudos que se propõe investigar as relações e comportamentos complexos e subjetivos como os que ocorremno âmbito escolar".

Ométododeveestarmuitopróximodoobjetivodoestudo,portantodevemosnosariscarporcaminhos, sem medo de errar, mesmo que eles tenham sido pouco percorridos. Oestudotoma-seárduo; pesquisar significaresolverproblemase, muitas vezes, sofrercomas nossas limitações, mas descobrirquenossacapacidadederesolvê-lospodeiralémdoqueimaginávamosé pordemais gratificante.

A escolhadeumestudodotipoetnográficoocorreu pelofatodocontextoestudadoserumaescolinhaesportiva, ondeencontramos ações pedagógicas desenvolvidas por treinadoresque têm suaformaçãocomo professoresdeEducaçãoFísicaousãoacadêmicosdesta área.

EmMolinaNeto(1999.p.107)lemosque:

"A etnografia vemencontrando, noâmbitoda educação, umterrenofértil para o seudesenvolvimento, principalmente porque os enfoques sistematicamente utilizadosnas pesquisas educativas nãooferecem respostas satisfatórias parauma série de questões, que vêmprogressivamente se configurandoem relevantes problemas de pesquisa".

Paraumamelhorcompreensãodoprocessodeinvestigaçãoe seguindoas orientações metodológicas que definemomodeloqualitativo, definiremosasfasesque compõemesteprocesso.

\section{Fases do processo de investigação}

AsfasesdoprocessodeinvestigaçãotiveramcomofundamentaçãoteóricaosestudosdeNegrine(1993)que se caracterizou pordividir otrabalhoemcinco fases distintas:
Quadro 1. Fases do processo de investigação

\begin{tabular}{|c|c|}
\hline 1 a fase & $\begin{array}{l}\text { Definição da área de estudo: } \\
\text { a) esodha db tema; } \\
\text { b) definição do prddlema; } \\
\text { c) definição dbs ddjeivos db etudo; } \\
\text { d) ddimitação des quetões da pesquisa; } \\
\text { e) daboração da fundementação teórica }\end{array}$ \\
\hline $2^{a}$ fase & $\begin{array}{l}\text { Definição des estratégias metodblógicas } \\
\text { a) definição do paradigna e do mácodb } \\
\text { de invedtigação; } \\
\text { b) definição dos partiaipantes }\end{array}$ \\
\hline $3^{a}$ fase & 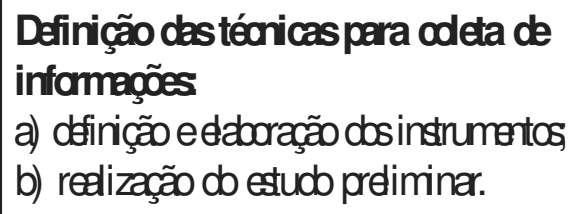 \\
\hline 4 fase & $\begin{array}{l}\text { Coleta de informações } \\
\text { Instrumentos utilizados } \\
\text { a) doservaçães } \\
\text { b) entreista; } \\
\text { c) análise de dbaumentos } \\
\text { d) dário de campo. }\end{array}$ \\
\hline $5^{a}$ fase & $\begin{array}{l}\text { Análise das informaçães } \\
\text { a) desorição da análisa } \\
\text { b) dsaussão e interpretaçãa. }\end{array}$ \\
\hline
\end{tabular}

\section{As categorias de análise}

Adescriçãoe análise dasinformações foramrealizadas apartirdas entrevistas, das observações, das anotaçõesdodiáriodecampo, análise dosdocumentos do estudopreliminare doestudopropriamentedito.Com estevolumedeinformaçõesobtidaseorganizadasem três painéis foram definidas 265 unidades relevantes. Acriteriosaleituradoextensomaterial recolhidoeorganizadoajudou nomomento daelaboraçãodascategoriasdeanálisedefinitivas.SegundoMinayo(1992), nãoé necessárioque essas categorias de análise, no estudo do tipo etnográfico, sejam definidas anteriormente. 
Portanto, arealizaçãodos procedimentosque foram adotadospossibilitou que surgissemasseguintescategorias deanálise, conforme mostramos a seguir:

1) Comunicaçãoentrecriançase pais sobremotivos queoslevamabuscaràescolinhaesportivadebasquetebol;

2) Comunicaçãoentre paise treinadores sobreapropostapedagógicadaescolinha;

3) Comunicaçãoentreascrianças, os paise otreinador,nas aulasenoseventosesportivos.

No presente artigo, para adequar-nos as normas de publicaçãodarevista, epelotrabalhoterficadoextenso, colocaremos a análise einterpretação da terceira categoria de análise que se refereà comunicaçãoentreascrianças, os paise os treinadores, nas aulas enos eventosesportivos.

Comunicação entre as crianças, os pais e o treinador, nas aulas e nos eventos esportivos

A terceira categoria de análise que surgiu a partirdas informaçõesrecolhidas ficousubdivididaem:

a) Acomunicaçãoentre treinadoresecrianças na visãodospais.

b) Acomunicaçãoentre treinadoresecrianças navisãodascrianças.

c) Acomunicaçãoentretreinadoresecrianças navisãodostreinadores.

d) Acomunicaçãoentre criançase paisnavisãodos treinadores.

e) Acomunicaçãoentre criançase paisna visãodas crianças.

f) Acomunicaçãoentre criançase paisna visãodos pais.

g) Acomunicaçãoentre treinadorese pais na visão dospais.

h) Acomunicaçãoentre treinadorese pais na visão dostreinadores. i) Acomunicaçãoentre paise treinadores na visão dascrianças.

A comunicação entre treinadores e crianças na visão dos pais

Aorealizarmosolevantamentojuntoaos pais sobre comopercebiamacomunicaçãoentreotreinadoreas crianças durante as aulas e os eventos, constatamos que:

Nas aulas amaioria dos pais entrevistados concordavam comotipode comunicaçãoque se estabelecia entre otreinadore as crianças.

Podemos exemplificaresselevantamentocomaentrevistadeGeraldo, paideBruno:

Nessa parte eu to bem satisfeito da relação do professor comos alunos, porque eu vejo que ele é uma pessoa que ele sempre procura incentivar os alunos e nãoé daqueles professores que ficamatucanando o aluno, ele dá, ele procura darforça dentro das suas possibilidades. (entrevistacom Geraldo,e.p.d.25-11-01).

Acomunicaçãodostreinadorescomascrianças, duranteasaulas, segundoos pais, nãosãopercebidasdamesmamaneiranoseventosesportivos. Ospaisentendiam queacomunicaçãodos treinadores comas criançastinhamqueserfeitasatravésdecondutasorientadas para atarefa, ondeprevalecemmaispressõesemaiscobranças.SegundoBeckerJr.(2000a), essemodelotemcomo finalidadeorendimentodoatleta, esepreocupamcom odesenvolvimentodesuashabilidadesfísicas, técnicas, táticase psicológicas. Umterçodos pais entrevistados nãoconcordavamcomamaneiracomootreinadorse comunicavacomascrianças, conformeaentrevista:

"Éalgumas vezes as crianças ficam meio abandonadas nos campeonatos, porque os professores ficam de juizou organizando o campeonato então as crianças ficammeio abandonadas no campeonato, mas como entre eles estãobemintegrados eles conseguemsuperar essadificuldade. Meiofalha, meiofalha, porque elenão fica muito com as crianças, então eu acho que as crianças acham falta da comunicação do professor ali estimulando, um pouco falha nos campeonatos eu acho."(entrevistacomBetina, e.p. 16-07-01). 
ConcordandocomaidéiadeBetina, ospais Femanda eGeraldoqueriamque os treinadores fizessemmais cobranças a seus filhos, oque vai de encontroàpropostapedagógicadoquepropõeaescolinhaesportiva queéoesporte-participação.

Nessemomentodadiscussão, verificamosquemuitos paisentrevistados concordavam comacomunicação dostreinadoresnas aulase discordavam comoestesse comunicavamcomascriançasnoseventosesportivos. Evidenciamos a contradiçãodos pais ao desejarem comunicações diferentes dotreinadornas aulasenos eventos, semperceberemasconsequiênciasque essa condutapoderiatrazerparaseusfilhos.

\section{A comunicação do treinador com as crianças na visão das crianças}

Paraascrianças dapesquisa, ostreinadores, em geral, possuiamumaboacomunicação, priorizandoorelacionamentoeaparticipação. Oprofessor apresentava uma conduta orientada para o relacionamento e a comunicaçãoera feita através de reforços positivos. Através daconversacomascriançase asobservações dasaulas,refletimossobre umcomponenteimportante da comunicaçãoque, segundo Weinberg e Gould (2001), ao se referirem ao reforço positivo ereforço negativocomoabordagemqueinfluemnocomportamento,falam-nosnaabordagem positiva, aumentandoaprobabilidade de fazercoisas desejáveisnofuturo.Inversamenteàpositiva, aabordagem negativafocaliza-seempunir.

Segundoaanálisedasinformaçõesqueobtivemoscom aentrevistadas criançaséqueacomunicaçãodostreinadores que observamos as aulas ocorria através de reforços positivose que as crianças sesentiam gratificadoscomissoquemesmoeleserrandootreinadoros apoiava. Constatamos através dasentrevistas quehaviacriançasqueestavamnaescolinhaháquatroanos emesmoaquelasquenãoqueriamobasquetebol,entraram porque eraoesportequetinha vaga, permaneceramportergostadode praticá-lo.

\section{Comunicação entre crianças e trei-} nadores na visão dos treinadores

Asentrevistasrealizadascomos treinadores possibilitaramfazerumareflexãoemrelaçãoàcomunicação dos treinadores comas crianças na visão desses treinadoresnas aulasenoseventosesportivos. Deacordo comostreinadores, tambémhouve umaunanimidadeemrelaçãoàcomunicaçãodosmesmoscomascrianças. Segundoeles, acomunicaçãocomas crianças éboa, apartirde umaconduta orientada para orelacionamento.

Essacomunicaçãofoi verificada, também, através de nossaobservação:

"Otreinador estápróximo das crianças que estão esperando para entrarnojogo. Olhaojogo enão semanifestamuito. Quando trocaumjogador elogiao que sai epassaamãonasuacabeça”. (obs. daaulade Antônio, e.p. 24-11-00).

NasaulasdeAntônio, verificamosalémdeledarreforços positivosàscrianças, quandoelesestãorealizandoalgumaatividade, eleosescutavaativamenteeissopudemos verificar,quandoreuniaascriançasnocírculo,todossentadosnochãooumesmoempé.Aescutaativasegundo WeinbergeGould(2000), queenvolveacomunicação não-verbal, eraverificada, quandoAntônioescutavaseus alunoseficava, olhandoemseusolhos,quandoestavam falandoefazendoacenoscomacabeça,confimandoque estavaentendendooqueestavamdizendo.

As aulasque observamos dostrêstreinadores, tinham umacondutaorientadaparaorelacionamento,demonstrandopreocupaçãocomasrelaçõesinterpessoais. Noseventos, nem sempreacomunicaçãodos treinadoresqueparticiparam preocupou-secomorelacionamento, eas finalidades doseu trabalhoforamoesporte-participação.

Fernandofoiumdos treinadores queentrevistamos, semque observássemos suas aulas. Foi incluídono estudo pelasuarepresentatividade, pois elefezparte deumeventoquenósobservamos. Traziaascrianças querepresentavamumclubeesportivodacidade.Fa- 
lamosaelequeestávamos realizandouma pesquisae que gostaríamos de conversar.Perguntamos qualera o objetivo ao trazer as crianças para jogar nesse encontrodebasqueteboleem suaentrevista disse-nos o seguinte:

"Nesses campeonatos eu colocomeusjogadores reservasparajogar, pois os paisme cobram que seus filhos estão na escolinha e não jogam, que eu não poderia fazernum campeonato oficial, poisnósiríamos perdere também para formar um grupo, mas aqui eles não aprendemnada." (entrevistacomFernando, 25-11-00).

AtravésdorelatodeFemando,foipercebidaumadiferençade suas finalidades aoparticipardoEncontrode basquetebol,emrelaçãoàs finalidades doesporte-participação,indo deencontroà propostado programa deiniciaçãodaSME.

Mesmoumtreinadorque se diziacoerentecomapropostadaSMEdoesporte-participação,demonstravasua incoerênciaatravés dasua comunicaçãonão-verbal. Primeiramentecolocaremosa entrevistaeaseguiro queobservamos noeventoemrelaçãoàcomunicação não-verbal:

"Bom, aminha comunicação. A primeira coisa que eu passo praeles que eunão quero sertodopoderoso, dono daverdade, que as idéias devem virtanto deles, quanto minha como, uma coisa que eu digo se existe algum prejudicado oufavorecido são as criançase eles devem me ajudar a construir uma boa aula, bom, a questão, eu entendo que a questão do basquete, ele éummeio que a minha visão não se limita à questão humana da formação da criança, trabalhando junto com os pais, escutandoasnecessidades dos alunos, os objetivosnão devem satisfazeroego do professore simasnecessidadesdoaluno". (entrevistacomDiegoe.p.d.25-11-01).

"Diego fica, em pé, na beira da quadra, fala para as crianças:" Queméo armador? Calma gente!" Pede calma, abre os braços, sacode a cabeça, desaprova a atitude de uma criança que está no grupo. A criança colocaasmãosna cabeça. (obs: Encontrode basquete, 25-11-00).

Acomunicaçãonão-verbal de Diego vai aoencontro doquediz(WEINBERGeGOULD,2001).Segundoessesautores, as pessoas muitas vezes nãotêmconsciên- cia dos indícios verbais que elasusam parasecomunicare tambémàsvezesignoramosindíciosnão-verbaiscomquese deparam.

Asobservaçõesqueaseguirdescreveremosreferem-se aestaformadecomunicaçãonão-verbal:

"Estouobservando o evento enoto que há equipes que estão vestidas comjalecos e outros estão com uniforme completo. Não havia um uniforme padrão para todas as equipes. Diego trouxe seus alunos todos uniformizados".(obs. doevento 15-10-01).

Aoobservarmoscomoas crianças estavam vestidas, pensamos sobre umaformadecomunicaçãonão-verbal que é a aparência pessoal, a forma visual como nósnosapresentamos(DELPRETTE, 1999). Aaparênciafísicaéumaformadecomunicaçãonão-verbal eatravés denossarouparevelamos muitas coisas. SegundoDiego, oencontrodemini-basquetebol nãodeveria ter pressão de um campeonato. Nanossa opiniãoessacomunicaçãovisual,quantoaouniformedas crianças trazidas por Diego, demonstrava uma conotaçãodecompetição, esuaequipe seapresentava comose fossem "atletasemminiatura".

NaentrevistaquefizemoscomotreinadorDiegofoirelatadopor eleque suacomunicação comas crianças visavaumacondutavoltadaparaorelacionamento,mas aoobservarmosestetreinadoremtrêseventosesportivos narealidade isso não veioaacontecer, através de sua comunicaçãonão-verbal. Portanto, foi percebidoque nãoexiste uma confirmaçãoentreoqueelerelatouea suacomunicaçãocomas crianças duranteoseventos. Percebemosumacomunicaçãoambígua ${ }^{3}$ deDiegoem relaçãoàs criançase umadiferença de finalidades de Fernandoemrelaçãoaoesporte-participaçãoindode encontroàpropostadaSME.Acomunicaçãodealguns treinadores aoparticiparemdoseventosiadeencontro àpropostadaSME, poisseobservaramcobrançasderesultadosnacomunicaçãonão-verbal dessestreinadores. Oque podemosinterpretarnessemomentoéque existeum limitemuitotênue entreoesporteparticipaçãoeacompetiçãodifícil desepararquenemmesmoos treinadoresconsegueminternalizar. 
Aindareferenteàterceira categoriadeanálise, quanto àcomunicaçãoentre paise crianças na visãodostreinadoresasubdividimos:

\section{Comunicação entre pais e crianças na visão dos treinadores}

Ostreinadoresforamunânimesemafirmarqueos pais participavam pouco das aulase alguns foram, além disso, nos dizendoque queriam uma maior aproximaçãocom esses pais. Istoveioase confirmarcom as nossasobservaçõesdasaulase pelamaioriadasentrevistasque conseguimos realizarcomos pais, emum eventoesportivo.

Oscontatoscomos paiseramfeitos atravésdascrianças, maselesnosrelatavamqueseus paisnãopoderiam vir por compromissos profissionais. Segundo Samulski(1995), os pais têminfluência nas atividadesesportivasdeseusfilhos, poismuitas vezesproporcionamajudafinanceira, levame trazemas crianças precisandoadequarsuas atividadescomos treinamentoseascompetiçõeseaindaproporcionamajudaemocional aos seusfilhos.

Quantoà participaçãodos pais nas aulas, elaaconteciaquandoesses paisdeixavamseusfilhosnaescolinha edepois eles voltavam sozinhos; esses pais nãoficavamolhandoas aulas. Jáos pais que assistiam às aulas ficavam sentadosnaarquibancada, quietos, olhando, conversandocomoutros pais, fazendoalgum trabalho manual.Para Carla, a treinadora, a pouca participaçãodos pais tema vercoma maior autonomia das próprias crianças, pois eles permitiam que elas andassemsozinhas, muitas vezesatéporumaquestão denecessidade.Elanosrevelouqueesteesportecomunitário recebia crianças de todas as classes sociais e que as crianças de classes mais baixas, os paisos deixavamandarsozinhos mais cedo. Geralmente oque aconteciaéque os dois trabalhavam fora enahora das aulas estavam trabalhando. Emnossas observaçõesnos deparamos comofatodemuitas vezesalgumas crianças que vinham para o basquete traziam juntoumirmãopequeno,equeeramresponsáveispelo seucuidado.

Nasentrevistas realizadas, verificamos aexistênciade paisque assistemàs aulas sónoinício, quandoinscreviamascriançasnaescolinha; depoisas criançaseram levadas até a porta e muitas vezes vinham sozinhas. Algunspaistelefonavamparasaberseseusfilhos mais novostinham chegadobemoufazendo-os telefonar quandochegavamaoginásio. Ospaistinhampreocupaçãocomas ruasmovimentadasquecircundavamo local das aulas; quando as aulaseram realizadas nas praçasem que os filhos moravam perto, não existia essapreocupação.

Muitasmães também trabalhavamforaparamelhorar a renda familiar, por isso tornava-se impossível acompanhar ofilho; ehavia aquelasque tentavam conciliarotrabalhocomas atividades dos filhos:

\begin{abstract}
"Quando eu posso sim, porque eu trabalho, né, então sempre que dá eu dou uma fugidinha pra assistir aula vêcomoéqué, principalmente no início, praver, gosto de conhecer o professor, vê como que éo relacionamento etudo". (entrevista comEliane, e.p.d.25-11-01).
\end{abstract}

Presença marcante nas aulase nos eventos foi à avó Andréia; observamosque existehoje umamudança decomportamentoemalgumas avós. Essaeraatleta da terceiraidade, na modalidade de basquetebol,e haviaincentivadoseunetoparaoesporte.

\section{“Assisto todas fui até lána Vila Elizabethlevar ele pra jogar um sol que bramia, ele foi de ônibus e eu fui de ônibus de linha, levando água pra ele nos confins do mundo”. (entrevistacom Andréia, e.p. 11-07-01).}

Acomunicaçãoentre criançase paisduranteas aulas eramarcadopela ausência destes pais nas mesmas. Nasnossas observações, houveumaefetivaparticipaçãodeduas avósnas aulase nos eventos esportivos.

Noseventosesportivos, deacordocomasnossasobservações, aparticipaçãodos paisaconteciacommaisfrequiênciadoquenasaulas. A presençadospaisnasaulas segundoaanálise deinformaçõesnãofoi significativa, porquenesseshorárioselesestãotrabalhando. 
Comunicação entre pais e crianças nas aulas e nos eventos na visão das crianças

Atravésdasentrevistas querealizamoscomas criançasecolocaremos aseguir, pode ser vistocomoeraa comunicaçãodospais comascrianças:

"Devezenquantominhamãevem, omeupainãoque ele estátrabalhando”. (entrevistacomCarlos,e.p. 18-07-01).

"Não, a minha mãe as aulas ela não pode, por causa que ela tá trabalhando, mas quandoé campeonato sim, nosfins de semana ela vemme verjogando". (entrevistacomOsório, e.p.d.26-10-01).

Aofazeremreferênciaàcomunicaçãodos pais, ascrianças nos relataram que elesnãopodiam viràsaulas, porqueerahorário de trabalho.Percebeu-se através da fala das crianças o quanto significava o pai ou a mãeteremumemprego,emumaclasse socialondeo desempregoémuitogrande. A criança faza a leitura dessanecessidadeeprovavelmentecompreendeque para o pai ou a mãe, estar ali durante as aulas, seria impossível.Emrelaçãoàcomunicaçãodos paiscom as crianças nos eventos, através das nossas observações, podemos dizerqueeles compareciam mais do que nas aulas. Isso seconfirmou pela maior quantidade deentrevistas que conseguimos realizarcomos paisnoEncontrode25denovembrode2001.Asobservaçõesquefizemos doseventos,emrelaçãoaospais,é que ir auma praça num final de semana, ir atéo ginásioonde ocorriaumevento, faziaparte deummomentodelazeraque os pais sedavamodireito.

Carolinaaofalardacomunicaçãodosseuspaisemrelaçãoaelanoseventos, dissequesesentiaincentivada, quandoelesestavamolhandoe atémelhoravaseudesempenho.Paraalgumascriançaséimportanteapresençados paisnomomentoemqueestãojogando.

"Vão, nem sempre, mas vão. A elescomeçam torcerpra mim, né, pra mim ganhar, pra mim melhorar meu time, me sinto muito bem, daí assim que eu reajo, começo ajogarmais." (entrevista com Carolina, e.p.d. 26-10-01)
Omesmosentimentoqueteve Carolinacomapresença de seus pais,não aconteceu com Gilberto que se incomodavacomapresençados seus pais olhandoo seujogo.

Oqueocorre, segundoBeckerJr.(2000b),équealgumascrianças apresentamníveis de ansiedadee perdemoequilibrioemocionalcomumareduçãogrande doseurendimento, quandoestãonapresençados pais. Porém, outras crianças nãoseincomodam.

"Assime e fico com um pouco de vergonha, assimaté eume sintomelhor quando eles não tão, né". (entrevistacom Gilbertoe.p.d.26-10-01).

As análises dasinformaçõesemrelaçãoàcomunicaçãodas crianças com os pais possibilitaram queentendêssemosopapel particularmenteimportantedelesnaexperiênciaesportivadosseusfilhos. Asatitudes ecomportamentos dos paistêm efeitosimportantes, tantopositivoscomonegativos, sobreoenvolvimento noesporte, a motivação, auto-estimaea saúdemental de atletasjovens.

\section{Comunicação entre crianças e pais na visão dos pais}

DeacordocomMachado(1997),podemosencontrar doistiposdetorcidanocontextoesportivo: asilenciosae aagressiva. Paraesse autormuitas vezes aquele familiarquefica caladonaarquibancada podefazer parte de umatorcida silenciosatão prejudicial àcriança, quantoà torcida agressiva, pois este familiar, quando chega em casa, naintimidade, éque descarregao que gostaria de ter ditodurante ojogo. Oque encontramosimplícitonaentrevistadopai Maurício:

"Mais de acordo com a minha disponibilidade eu às vezes assisto as aulas dele, dentro dopossível, se eupudesse assistiria sempre pra dar um incentivo ao meu filho e também nós trocarmos idéia em casa, apesar deleterprofessorbemexperiente, né, masésempre, mas é sempre bom o pai de fora dar uma pincelada, então dentrodopossível euassisto”. (entrevistacomMaurício, e.p.d.26-10-01). 
Jánocasodatorcidaagressiva, estaficatodootempo dojogosemanifestando,masnãofoioqueencontramos. Ospaisficavamquietosolhandoosjogos, quandomuitoalguns aplausos, masnãoforamobservados gritandonasarquibancadas.

Foiemumdesseseventosqueconseguimos verreunidos uma maioriade pais, dando-nos aoportunidade derealizaromaiornúmerodeentrevistas.

\section{Comunicação entre treinadores e pais na visão dos treinadores}

Deacordocomaanálise de informações, apresença dos paisnas aulas aconteciararamenteenos eventos ela ocorriacommaior frequiência. Issofoi revelado pelos treinadores, quandoperguntados comoeraasua comunicaçãocomospais.

Bemardo, otreinadordaturmadamanhã, relatouque poucospaisoprocuravamparaconversar, pois dificilmente algum pai traziaa criança. Às vezes porconta de um problemacomalguma criançaopai ou amãe vinhame ele tinha a oportunidade de conversar. Os paisalegavamquetinhamosseuscompromissosprofissionaisenão dispunham de tempoparaficar assistindoàsaulas. Essetempoeradado, quandoascriançasiniciavamnaescolinhaesportivatrazidaporelese oprofessortinhaa oportunidade de conversareexplicara suametodologia de trabalho.Éoquenosfalou Diego sobre a comunicaçãodele com os pais eram poucosos paisquecompareciamàsaulas,nessafaixa etária, abordada pela pesquisa; apenas cinco ou seis paissefaziam presentesàsaulas.

Eugêniotrouxeumgnupodaescola,queelecompôsa partirdas aulas deEducaçãoFísica; ele disseque os paisnãotinhama articipaçãonas aulas porse tratar deum grupoescolar.Através da nossa experiência, podemos verificarqueaescolaaindaseconstituiem um lugar em que os pais não participam das aulas. Quandosãochamados, atémesmoparareuniões, sua presençaémuitopouca. Não se vênaescolanenhum paiassistindoas aulasdeseufilho, mesmoas deEducaçãoFísica.
Nas observações dasaulasquefizemos doestudopreliminare doestudopropriamente dito, a presençados pais era muitorara, comofoi mencionado anteriormente.

Apresençados paisnosencontrosdebasquetebolaconteciadeformadiferenciadade outroeventoesportivo que tínhamos assistido atéentão. Os pais nos finais dosjogoseram convidados pelos treinadoresparafazeremoslanceslivreseospontosqueelesfaziameram convertidos paraasequipes de seusfilhos. Observouseque existiaumincentivodostreinadoresparaque todosospais entrassememquadraparaparticipar.As crianças ficavam torcendopelos pais,nabeiradatela.

"Muitas vezesémostrarparaessespaiscomoédificil ta naposição de dentro da quadra, com todo umaparato assimde uma estrutura diferente do que eles estão acostumados, mas ta do lado deforaéuma coisa..." (entrevistacomAntônio,e.p.29-06-01).

Os paiseramchamadosaparticipardoseventos atravésdeumacomunicaçãoescritaqueofilholevavapara casa. Quandooeventoocomiaemoutrolugar,ospais eram chamados paraumareunião.Essas reuniões aconteciamantesdeumeventomarcante.Carla, quandose referiu às reuniões quefaziacomos pais, disse queelescompareciame, senão pudessem, mandavamavisar.

Diego,referindo-seàsreuniõesquefaziacomospais, considerava-as muitoproveitosas, poiselas ajudavam a fazer os paisentendercomo deveriam ser as suas condutasduranteoseventos.

Todosos treinadoresforamunânimesemafirmarque os paisnoiníciodos trabalhos dasescolinhas, durante os eventos, cobravam mais dos seus filhos, mas no momentoemqueostreinadoresconversavamcomeles, as suas cobranças em relação aos filhos diminuía. Observou-seque durante as aulas isso ficava difícil, poistudotinhadeserconversadomuitorapidamente.

\footnotetext{
"Antônio termina uma aula e começa a outra, uma mãe se aproxima dele para conversar, os alunos estão entrando em quadra e pegando as bolas, Antônio fala rapidamente com a mãe" (observação de Antônio, 24-11-00).
} 
Oquefoi constatadoem relaçãoàcomunicaçãodos treinadorescomos pais, atéo momentodaanálise dos dados, équeos treinadores tinhampreocupaçãocom queestecontatofosseefetivado, masqueosmomentos erammuitopoucos paracomunicarem-secomos pais. Teriamdesercriadosnovos espaçosde discussãocom asfamílias, além dos poucosque jáexistiam.

\section{Comunicação dos treinadores e pais na visão dos pais}

Geraldofoiopaiquemaisobservamosnasaulas.Emcertaépocadanossainvestigação,nãovimosmaisGeraldo, massuaesposaestavasemprepresenteolhandoasaulas deBruno,naescolinhaháquatroanos, segundoopai.

Fernandasentianecessidadede sabermaiscoisasem relaçãoàescolinhaemquehaviacolocado seu fillho. Jáhaviatentadomaisinformações,masnãoficoucontente comoque obteve, queria mais atenção. Naentrevista, estavaangustiada porque seu filhonãoqueria virmais para o basquete e ela não sabia oque fazer,nãoentendiaporqueissoaconteciacomseufilho.

\footnotetext{
"Outra coisa eles deveriamfazer reuniões comos pais, divulgarmais o esporte, divulgarmais obasquete, divulgar mais o que tem aqui dentro, né, eu não ouço nada às vezes lá na diretoria tu pergunta eles ficam meio na dúvida..." (entrevista com Fernanda, e.p.d. 26-10-01).
}

Emrelaçãoà comunicaçãodos treinadores comos pais, Eliane, a mãe de Diegoque tinha aulas debasquetebolnoparque, relatouqueascomunicaçõeseram feitasno início das aulas, através da coordenadora,e depois, porbilhetesenviados pelas crianças:

"Não, daísóéfeito sóo inicial coma coordenadoraque cuida ali do Parque, e daí ela nos explica como vai ser feito etudo, ecadavez que tem campeonatoo professor manda bilhete, ou avisa pra eles, sempre quando vem ohorário, local quem querparticiparpode" (entrevista comEliane,ep.d.25-11-01).

Mauricio, nãoserecordavadetervindoaalgumareunião, pois segundoelequem trouxera seufilhoparaa escolinhahaviasidosuaesposa:
“Olha que eume recorde, não e eunão sei se euestava junto, se eu estavajunto eunão me lembro mais, mas poderiaatéquem sabe, estar aminha esposa, como eu tefaleino início, foi ela omotivo que trouxe omeu filho pracáfoi idéia da minha esposa, ela que viu isso" (entrevistacomMauricio,e.p.d.26-10-01).

Betinaeraumamãepresentenasaulasdeseufilho, Carlos, e, segundoela,jáhaviaparticipadodealgumasreuniões. Conheciaasfinalidadesdoesportequealisedesenvolvia; percebemosqueos problemasdeobesidadedeseufilho eraalgo que a angustiava e que iam além do que a escolinhapoderiaoferecer. “...participeide algumas reuniões...” (entrevistacomBetina,e.p.d.16-07-01).

AocontráriodeBetina, aavóAndréiahaviacolocado seu neto há três semanas no basquetebol, játinham idoaumcampeonato, mas desconheciaapropostada escolinha, e não tinhaassistidoa nenhuma reunião, poisotreinadorprometeu conversarcomela, masnão haviaacontecidoestareunião:

“... eu tenho que falar como professor, eunão tive entrevista como professor, apenas apresentação, e eunão queromemeter, pra ta pesquisando, isso, aquilo, aquilo, outro, tenho que esperarpor ele, eu sei que tem um dia que ele vaimarcar comos avos e pais pra conversar..." (entrevistacomaavóAndréia, e.p.d.11-07-01).

Através dos relatos dos paise familiares das crianças, percebemosquantoàcomunicaçãocomos treinadores, os pais sentiamanecessidade de teremmaismomentos paradiscutirem as questões relacionadas ao programaemque seu filhoestavainserido. Essanecessidaderevelada pelos paisératificada, através da importância de se implantarno projeto de iniciação esportiva, um programade assessoramentoaos pais. Esseprogramase justificapelainfluênciaqueestespais exercematravés desuapresença, omodocomoconduzemseuscomentáriosouopiniões(Gordillo,2000). Achamosimportanteiralémdasinformaçõesdospais emrelaçãoàcomunicaçãocomostreinadoreserelataroque pensamestes profissionais, quantoaterem ummomentoparadiscutiressasquestões, atravésdas entrevistascomospróprios treinadores: 
“Emgeral issonão, sóseo pai, quandoo paivem, aprimeiraaulaelevem trás e conversa, elemeperguntamuitas coisas, daíeu consigo conversar, mas ainda a gente nãotemessemomento, sóquando ele vaiapróximareuniãoouquandoele participadoprimeirocampeonato, ai opaiconversa"(entrevistacomCarla,e.p.d.23-11-01).

ParaDiego,apoucaparticipaçãodospaisnasaulas,ocorriaporqueelestinhamcompromissosprofissionais, ospais comquemeleconseguiacomunicar-seerampoucos:

Ratificandooquediziamos paiseostreinadores, Gordillo (2000)refere-seaos trabalhosquesãodirigidos aostreinadoresnointuitodeorientá-los acomoenfocarasuas relaçõescomos paisdemaneiraqueissopossapermitir umacomunicaçãoadequadaeeficaz, dandoconselhose orientaçõesdecomoinfluirnasatitudeseatuaçõesdeles.

A comunicação entre os pais e os treinadores na visão das crianças

Atravésdasinformaçõesqueobtivemosnasaulas,quanto àcomunicaçãodospaiscomostreinadores, segundoas crianças, elasemsuamaiorianosdisseramqueraramente ostreinadoresfalavamcomospaiseessescomeles.

Demétrio, ofilhodeFernanda, disseque suamãeveio falarcomotreinador, quandohouveumdesentendimentodelecomum coleganaaula. Ascrianças relataram que os pais vinhamàs reuniões antes docampeonatoeconversavam comotreinadorouqueacomunicaçãoerafeitaatravés de bilhete, paraelescompareceremàreunião.

Paraascrianças, acomunicaçãodos treinadorescom seus pais aconteciaquandoestes tinhamdeentrarem quadraparafazeros arremessos. Raramente os treinadoreseospaisconversavam.

Atravésdasnossasobservações, percebemosqueraramenteumpai vinhafalarcomostreinadores. Equandoissoocorria erafeitorapidamente, porque a outra turmajá estava esperando parainiciar a aula e nos eventos os paisficavamolhandoojogoenãofalavam comelese amaior aproximaçãodos pais comos treinadores eraquando eles entravam em quadra para fazerosarremessos.

\section{Considerações finais}

- Existiapoucaparticipaçãodos pais(pelas suasausências)nocontextodas aulas daescolinha;

- noseventos, apresençados paiserasignificativa;

- ostreinadoresconsideravamimportanteteremum espaçoespecificoparamelhoraremacomunicaçãocomospais;

- todosospaisexpressaramanecessidadedeumespaçoparacomunicarem-se comos treinadores;

- apercepçãodas criançasé de que, raramente os paise ostreinadores secomunicavam;

- muitos paisrelataramquenas aulas, a habilidade decomunicação, dos treinadores com as crianças eraadequada, masnos eventosesportivosessanão ocorriadamesmaforma;

- acomunicaçãoverbalenão-verbal dealgunstreinadoresnoseventoseraincoerentecomaproposta doesporte-participação; demonstrandofinalidades divergentesaoparticiparemdoseventos;

- para as crianças a comunicaçãodos treinadores, nas aulas enos eventos, ocomiaatravés dereforços positivos.

Aofinal dessainvestigação, frenteaosresultados apresentados, sugerimos que oprogramadeiniciaçãoesportivaestudadodevaincluiraassessoriade umprofissional daáreadePsicologia doEsporte, paraapoiar ostreinadores, paise crianças, comissobuscaroampliaçãodahabilidadecomunicativaentreosmesmos. Esteprocedimento, queconsideramosinovador,deverácontribuirparaaconstruçãode sentimentos deconfiançae decooperaçãoentreessatríade fundamental dodesportoinfantil: crianças, paise treinadores.

Hánecessidade defuturas investigaçõesemtodas as modalidadesquefazempartedoProgramadeIniciaçãoEsportivadaSME.

Sugerimosqueestudos similares sejamefetuadoscom jovensdaetapaevolutivadaadolescênciaemcujoperíodoinicial de(trezeaquinzeanos)estálocalizadoamaior incidênciadeabandonodoesportepeloserhumano. 


\section{Referências}

ANDRÉ,MarliE.D.A.de.Etnografiadapráticaescolar.Campinas:Papirus, 1995.BECKERJr.,Benno.ManualdePsicologiado Esporte exercício. Porto Alegre/NovoHamburgo: Novaprov,2000a.

ANDRÉ,MarliE.D.A.PsicologiaAplicadaà CriançanoEsporte.NovoHamburgo:FEEVALE,2000b.

ANDRÉ,MarliE.D.A.PsicologiaAplicadaaoTreinador.Novo Hamburgo:FEEVALE,2002(noprelo). BECKERJr.,Benno; SAMULSKI,Dietmar.Manualdetreinamentopsicológicopara oesporte.PortoAlegre:EDELBRA,1998.

DAVIS,Flora.Acomunicaçãonão-verbal.SãoPaulo:Summus, 1979.196p.DELPRETTE,ZildaA.P.Psicologiadas Habilidades Sociais: terapiae educação. Riode Janeiro: Vozes, 1999.

DELPRIORE,MaryLucyetal.ImagensdaFamilia-Históriada criançanoBrasil.SãoPaulo:Ed.Contexto,1996.176p.

ERIKSON,ErikH.Infânciae sociedade.RiodeJaneiro:Zahar, 1971.404p. GAELZER, Lenea. Histórico. Liderança Recreacional. As atividades de grupona recreação: formaçãodeclubes.2.ed.PoitoAlegre:UFRGS, 1985.

GORDILL,Alex.Intervençãocomospais.In:BECKERJJ:Benno (Org.).PsicologiaAplicadaa CriançanoEsporte. NovoHambungo:FEEVALE,2000.

MINAYO,MariaCeciliaS.Odesafiadoconhecimento:pesquisaqualitativaemsaúde.RiodeJaneiro:SãoPaulo:ABRASCOHUCIIEC,1992.

MOLINANETO, Vicente.Etnografia: umaopçãometodológica paraalguns problemas deinvestigaçãonoâmbitodaEducação FísicaIn:MOLNANETO,Vicente;TRIVINOS,AugustoNibaldo. (Orgs.).A pesquisa qualitativa em Educação Física: alternativasmetodológicas.PortoAlegre:Ed.Universidade/UFRGS/ Sulina, 1999.

MOLINANETO, Vicente.InstrumentosdePesquisaQualitati$v a$.(Aportesdeaula).Porto Alegre, 2000.

NEGRINE,Airton. “Juegoypsicomotricidade”. 1993.Tesis doctoral (Doutorado Didática y Organización Escolar) FacultaddePedagogiadelaUniversidaddeBarcelona, Barcelona, 1993.

NEGRINE, Aírton. Instrumentos de coletade Informaçõesna Pesquisaqualitativa.In:MOLINANETO, Vicente; TRIVIÑOS, AugustoNibaldo.(Orgs.).Apesquisa qualitativa emEducação Física: alternativasmetodológicas.PortoAlegre:Ed.Universidade/UFRGS/Sulina, 1999.
RECTOR,Mônica;TRINTAAlúizioRamos. Comunicaçãodo Corpo.2.ed.Petrópolis: Ática, 1993.

RODRIGUES, RejanePenna. UmabrincadeiraItinerante.In: RODRIGUES, RejanePenna. Iniciativas Públicasde Lazere Recreação em Porto alegre: alguns caminhos percorridos. RiodeJaneiro:Vozes, 2000.

SECRETARIAMUNICALDEESPORIESRBCREAÇÃOHLATR Diretrizes Pedagógicas.Porto Alegre:Inpress, 2000.

SAMULSKI,DietmarMartin. Psicologiadoesporte:teoriae aplicação pratica. BeloHorizonte: Imprensa Universitárial UFMG,1995.

TRIVIÑOS, AugustoNibaldoSilva. Introduçãoà Pesquisaem Ciências Sociais: a pesquisa qualitativa emeducação. São Paulo:Atlas, 1987.

WEINBERG,RobertS.;GOULD,Daniel.Fundamentosdapsicologiado esporte e do exercício. Traduçãode MariaCristina Monteiro.2.ed.PortoAlegre:ARTMED,2001.

\section{Notas}

* Treinadores: neste trabalho, quandoestivermos nos referindoatreinadores ou professores, tratamos daqueles que dãoaulas nasescolinhasesportivas, tantoLicenciadosem EducaçãoFísicacomoacadêmicos. Utilizamos apalavra treinadorporesseserumtermomais referenciadonaPsicologiadoEsporte.

***MestreemCiênciasdoMovimentoHumanoESEF/UFRGS. Professora de Graduaçãoda UniversidadeLuterana do BrasilULBRA

**** DoutoremPsicologia. ProfessordoDoutoradoemMedicinae Ciências doEsporte da Universidad de Córdoba/ Espanha e Professor Doutor do Centro Universitário FEEVALENovoHambungoRS.

${ }^{1}$ Conversacomumfamiliarde uma criança durante uma observaçãodeaula: dia24-11-00.

2 Asmensagensefetivas, segundoWeinbergeGould(2001), refere-seàsmensagensseficazes que ocorremnacomunicaçãoentreas pessoas.

${ }^{3}$ Oconteúdoverbal nãoestáde acordo coma sualinguagemcorporal (BeckerJr., 2000a).

Recebido:26/09/02

Aceito:30/12/02 